Article

\title{
Dynamic Time-Of-Use Pricing Strategy for Electric Vehicle Charging Considering User Satisfaction Degree
}

\author{
Qian Zhang ${ }^{1, *(\mathbb{D}, \text { Yue Hu }}{ }^{1}$, Weiyu Tan ${ }^{2}$, Chunyan $\mathrm{Li}^{1}$ and Zhuwei Ding ${ }^{1}$ \\ 1 State Key Laboratory of Power Transmission Equipment \& System Security and New Technology, \\ Chongqing University, Chongqing 400044, China; hu_yue@cqu.edu.cn (Y.H.); lcycqu@cqu.edu.cn (C.L.); \\ dingzhuwei@cqu.edu.cn (Z.D.) \\ 2 China Southwest Architectural Design and Research Institute Corp., Ltd., Chengdu 610042, China; \\ tanweiyu@cqu.edu.cn \\ * Correspondence: zhangqian@cqu.edu.cn
}

Received: 13 April 2020; Accepted: 2 May 2020; Published: 7 May 2020

\begin{abstract}
In order to solve the problem that the static peak-valley price for electric vehicles cannot truly reflect the relationship between electricity supply and demand, as well as the fact that the low utilization rate of renewable energy in the micro-grid, a dynamic time-of-use pricing strategy for electric vehicle charging considering user satisfaction degree is proposed, to achieve the goal of friendly charging for the micro-grid. Firstly, this paper researches the travel patterns of electric vehicles to establish the grid connection scenes and predict the controllable capacity of electric vehicles. Secondly, the charging preferences of different types of users are studied, and a comprehensive satisfaction degree model is set up to obtain different users' charging strategies. Furthermore, the paper raises a pricing strategy on account of the dispatching requirements of the micro-grid, and realizes the effective dispatch of electric vehicle charging load based on price signals. Finally, we gain the dynamic time-of-use charging price, using the strategy proposed above, and the economic benefits brought to the micro-grid and electric vehicle users are analyzed, which validates the rationality and effectiveness of the pricing strategy.
\end{abstract}

Keywords: electric vehicle; user satisfaction degree; charging preference; dynamic time-of-use charging price; micro-grid

\section{Introduction}

\subsection{Motivation and Background}

As environmental issues and energy crises have increasingly negative impacts on human society, targets such as energy conservation and emission reduction, energy efficiency improvement, and the effective utilization of renewable energy become research hotspots in the field of power system [1,2]. In recent years, as the representative for new energy vehicles, electric vehicles (EVs) are recognized as the main direction for the transformation and development of the 21st century automobile industry, owing to the fact that EVs are characterized by high energy efficiency, low $\mathrm{CO} 2$ emissions, and little oil dependence [3]. However, the uncoordinated charging behavior of large-scale EV owners will have a profound influence on the power system [4]. If effectively controlled, the orderly charging behaviors of EV clusters does not only realize the purpose of peak-shaving, but also solves the problems of low utilization rate of renewable energy and imbalance between power supply and demand, which will bring positive effects to the safe and stable operation of the electricity grid [5]. 
According to the investigation, the number of EVs in the U.S. will reach 1.8 million by 2020, and the proportion of EVs is expected to reach $51 \%$ and $62 \%$ of the total number of vehicles by 2030 and 2050 [6]. Considering the stochasticity of heavy EV charging load, it is necessary to fully explore the controllability of EVs in the time dimension, in order to decrease the huge impact of EV charging behaviors on the power system [7]. Reference [8] indicates that the uncertainty caused by battery degradation cost and real-time electricity price has a great influence on the economy of EV users. Reference [9] solves the parking-lot EV charging scheduling problem through a game-theoretic approach. Each EV acts as a player with the objective of maximizing its own utility function, and the change of electricity price seriously affects the equilibrium. As the temporal characteristic of EV charging load is closely related to the charging price mechanism, reasonable charging schedules can be arranged for EVs through the economic lever of charging price $[8,10]$. Furthermore, the micro-grid is a good platform for large-scale access of renewable energy generation and EVs to the grid, which can promote both sides [11]. Since the source and load of the micro-grid containing distributed generation and EVs have considerable uncertainty, which leads to the imbalance between power supply and demand and the low utilization rate of renewable energy, it is necessary to formulate an attracting tariff mechanism based on the dispatching demand of the micro-grid to availably guide the charging behaviors of a great quantity of EVs.

\subsection{Relevant Literature}

The price mechanism of electricity market, as an important basis for EV users to select charging strategies, has a significant impact on the results of load adjustment. Massive theoretical research has been made to develop the price mechanism for EV charging, and existing work can be generally classified into two aspects: (1) the peak-valley price [12,13]; (2) the dynamic time-of-use charging price, based on a supply-demand relationship. Among them, the constant peak-valley price can only reflect the basic situation of the daily load, but cannot properly regulate the charging price for scenarios such as a surge or sudden drop, which may lead to another peak load and affect the safe operation of the power system. With the help of dynamic pricing approaches, users can be encouraged to reveal their full flexibility, containing the flexibility in the charging duration, the amount of energy, and location can be addressed [14].

In order to solve the new problem that the peak-valley price may bring to the electricity grid, scholars have gradually carried out research in the field of dynamic time-of-use charging price for EVs. Reference [15] proposes an approximate dynamic programming feedback-based optimization method to tackle the problem of managing fleets of EVs, which verifies that the dynamic price compared with peak-valley price can effectively stabilize the load fluctuation and enhance the economy of the charging station. In addition to smart charging, dynamic price is a better approach than a constant time-of-use price to overcome the challenges related to an increasing penetration of EVs [14]. Reference [16] proposes the use of dynamic pricing, in order to reduce the costs of energy purchased in the energy market. In Reference [17], the scholars investigate the setting of dynamic price for different EVs charging deadlines with the objectives of maximizing the charging station operator's profit and minimizing the peak load. In addition, considering dynamic electricity price during daytime features significant stochastic, a two-stage approximate dynamic programming framework is proposed, to determine the optimal charging strategy for EVs in reference [18]. Based on the charging requirements of customers and system load profile, reference [19] presents a coordinated charging strategy for EVs, considering dynamic time-of-use tariffs to reduce the operational costs of the charging station and customer charging fees. According to the data of the output and load of renewable energy, reference [20] proposes the EV charging pricing strategy for the goal of balance between supply and demand from the micro-grid, without considering the response to the price from the perspective of EV users, but whether the effective dispatching of EVs can be achieved, depending on users' preferences and choices, to a certain extent. 
EV users will consider the inconvenience of electricity consumption, EV battery loss, cost, and economic benefits when participating in dispatching, as well as worrying about whether the strategy of charging can meet their travel needs. Reference [21] investigates, in a stated choice experiment, the charging behavior of the EV user, considering not only flexibility in the charging patterns, but also in the driving patterns. They conclude that there is a large heterogeneity in user preferences. However, studies in [16-20] assume that EVs strictly follow the dispatching order of the electricity grid, which ignores the influence of the preferences and personal choices of EV users on the dispatching results. Therefore, the charging price obtained by these studies is hard to achieve alongside the effective dispatching of EVs and still has great limitations in its application. From this point of view, the paper develops a dynamic time-of-use pricing strategy for EV charging, considering user satisfaction degree, so as to effectively adjust the charging demand of EV users with different preferences.

Meanwhile, the above research methods raised above only take into account the overall uncoordinated charging characteristic of EV clusters, but lack the in-depth exploration of the driving characteristics for the individual EV. Nevertheless, the accuracy of the actual controllable capacity of EVs will influence the final dispatching results. Thus, it is necessary to determine the controllable capacity of EVs based on the users' travel patterns and charging requirements.

Currently, due to the lack of consideration of EV users' charging preferences and choices, the dynamic time-of-use charging price cannot achieve effective dispatching of EVs, resulting in the lack of effective adjustment means for EV charging load when faced with load fluctuations in the micro-grid. Consequently, the charging price should be dynamically formulated and published according to the generation output and load conditions, so as to adjust the charging strategies of users with different charging preferences, which aims to solve the problem of a large imbalance between power supply and demand and effective dispatch of the EVs.

\subsection{Contributions and Organization}

Compared to existing works about dynamic pricing strategies of EV charging management discussed, EV users' economic and convenience preferences are considered, to determine charging strategies for different users in this paper. It is notable that dealing with the topic from the perspective of the user separates this study from the other studies in the literature. Based on the driving characteristics and charging preferences of users, this paper designs sub-item evaluation indicators, to represent the comprehensive satisfaction of EV users. Furthermore, a dynamic time-of-use pricing strategy for EV charging considering user satisfaction degree, which is implemented in the day-ahead, is proposed to achieve the goal of friendly charging for the micro-grid. Thus, the charging behavior of the EVs will not only achieve the goal of peak load shifting, but also stabilize the load fluctuation, and improve the utilization rate of renewable energy in the micro-grid. The main contributions in this paper are summarized as follows:

- The travel patterns of users are researched to establish the grid connection scenes of individual EVs, and a criterion for judging whether an EV is in controllable state is proposed to forecast the controllable capacity of large-scale EVs;

- The charging preferences of different types of EV users are studied, and user economic satisfaction degree and electricity convenience satisfaction degree are defined, to establish the comprehensive satisfaction degree model for obtaining different users' charging strategies;

- A dynamic time-of-use pricing strategy for EV charging, taking account of the choice of EV users based on the dispatching requirements of the micro-grid, is raised, which considers the demand response and realizes the effective dispatch of EV charging load based on price signals.

The remainder of this paper is organized as follows. In Section 2, several problem formulations to analyze the controllability of EVs are established. In Section 3, the calculation model of user satisfaction degree is presented. A pricing strategy for EV charging considering the preferences of EV users is 
proposed in Section 4. In Section 5, the method is verified to be effective, and the proposed conclusions are drawn in Section 6.

\section{Analysis of EV Controllability Considering Users' Travel Patterns}

The establishment of grid connection scenes and the prediction of controllable capacity of large-scale EVs aim to obtain the number and total controllable capacity of EVs that are in a controllable state during the dispatching period. The total controllable capacity is obtained by stochastic sampling of the Monte Carlo method, based on the analysis of travel patterns of individual EVs in this section.

Compared with the driving characteristics of buses, taxis, and official vehicles, private EVs are mostly used for commuting and daily entertainment between home and workplaces. Therefore, private EVs are utilized only $4 \%$ of the time in a day for transportation, thus, most private EVs are potentially available for dispatching of power system in the remaining $96 \%$ of time on weekdays [22]. Thus, this paper takes private EVs on weekdays as the research object to establish grid connection scenes and analyze the controllability of EVs in each time period. At present, the power supply means for EV batteries mainly include vehicle charging and battery replacement. This paper will study the management method of vehicle charging, due to its wider use in the field of private EVs than the battery replacement [23].

\subsection{The Establishment of Grid Connection Scenes of EV}

The grid connection scenes of EVs have uncertainty on the temporal scale, mainly due to factors such as the commuting time and the daily mileage [24]. This paper takes the following five parameters to establish the grid connection scenes of EVs: the time leaving home, the time arriving at the workplace, the time leaving the workplace, the time arriving home, and the daily mileage of EVs. According to the 2011 Beijing Traffic Development Annual Report, the probability distributions of travel time of private EV owners are fitted [25]. The graphs of the original data are shown in Figures A1 and A2 in the Appendix A, and the results show that the time leaving home and leaving the workplace obey the Cauchy distribution, while the time arriving at the workplace and arriving home obey the normal distribution. The corresponding expressions of probability density functions $f_{w, s}, f_{e, s}, f_{w, f}, f_{e, s}$ are shown in Equations (1)-(4), and the distribution functions are $F_{w, s}, F_{e, s}, F_{w, f}, F_{e, f}[26]$.

$$
\begin{gathered}
f_{w, s}\left(t_{1}\right)=\left\{\begin{array}{cc}
\frac{1}{1.2 \pi\left[1+5\left(t_{1}-7.3\right)^{2}\right]} & 0 \leq t_{1} \leq 7.5 \\
\frac{1.05 \pi\left[1+6\left(t_{1}-8.2\right)^{2}\right]}{2} & 7.5 \leq t_{1} \leq 24
\end{array}\right. \\
f_{e, s}\left(t_{2}\right)=\frac{1}{0.75 \pi\left[1+3\left(t_{2}-17.2\right)^{2}\right]} \\
f_{w, f}\left(t_{3}\right)=\frac{1}{\sqrt{2 \pi} \times 0.6} \exp \left[-\frac{\left(t_{3}-8.75\right)^{2}}{2 \times 0.6^{2}}\right] \\
f_{e, f}\left(t_{4}\right)=\frac{1}{\sqrt{2 \pi} \times 0.8} \exp \left[-\frac{\left(t_{4}-18.2\right)^{2}}{2 \times 0.8^{2}}\right]
\end{gathered}
$$

where $t_{1}$ is the time leaving home, $t_{2}$ is the time leaving the workplace, $t_{3}$ is the time arriving at the workplace, and $t_{4}$ is the time arriving home.

The daily mileage of EVs depend commuters' work and driving characteristics. Moreover, the driving characteristic of large-scale EVs is regular. Based on the results of 2009 National Household Travel Survey, it can be concluded that the daily mileage of EVs obeys the following normal distribution $f_{d}(x)$ [27]:

$$
f_{d}(x)=\frac{1}{x \sigma_{d} \sqrt{2 \pi}} \exp \left[-\frac{\left(\ln x-\mu_{d}\right)^{2}}{2 \sigma_{d}^{2}}\right]
$$


where $x$ is the daily mileage of EVs, $\mu_{d}$ and $\sigma_{d}$ are mean value and variance respectively, $\mu_{d}=3.2$, $\sigma_{d}=0.88$.

Assuming that the five parameters of individual EVs shown in Equations (1)-(5) are mutually exclusive, EV users' travel patterns can be simulated by Monte Carlo method, i.e., grid connection scenes. If the scale of EVs in a certain area is $N E$, the grid connection scenes of $\mathrm{EV}$ can be represented by the sampling matrix $Q=\left[W_{s} ; E_{s} ; W_{f} ; E_{f} ; D\right] . W_{s}$ is a $1 \times N E$-dimensional matrix of the time leaving home, $E_{s}$ is a $1 \times N E$-dimensional matrix of the time leaving the workplace, $W_{f}$ is a $1 \times N E$-dimensional matrix of the time arriving at the workplace, $E_{f}$ is a $1 \times N E$-dimensional matrix of the time arriving home, and $D$ is a $1 \times N E$-dimensional matrix of daily mileage of EV users. The elements in the same column of the sampling matrix $Q$ are the grid connection scenes of a single EV.

\subsection{The Controllable Capacity Forecast of Large-Scale EVs}

The establishment of grid connection scenes of EV is considered as the basic data for large-scale EVs' controllable capacity forecasting. According to the driving characteristics of EV users on weekdays, it is generally believed that the users will charge the batteries uncoordinatedly during the working period or in the time at home. It is supposed that the morning rush hour is $\left[W_{s, i}, W_{f, i}\right]$ and the evening rush hour is $\left[E_{s, i}, E_{f, i}\right]$. The charging period division of EV $i$ on working days is shown in Figure 1.

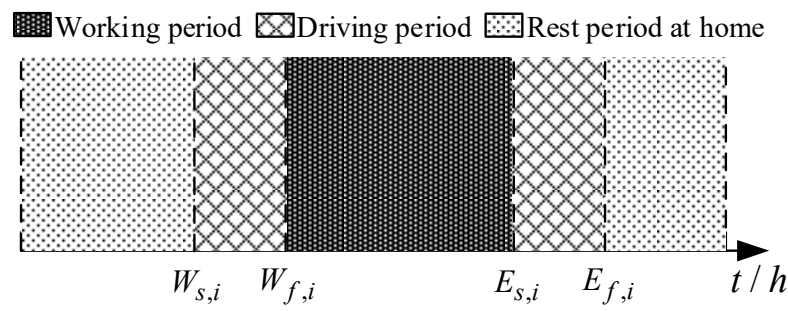

Figure 1. The charging period division of electric vehicles (EVs) $i$ on working days.

During the driving period, the private EVs are not in a dispatchable state, thus the controllable capacity is set to be zero. EVs can receive the dispatching orders from electricity grid at any time during the users' working hours at the workplace and rest hours at home, and select an appropriate charging strategy, according to their own demands. The number of idle EVs in the time period $\Delta T$ of the above two can be expressed by Equation (6):

$$
\begin{aligned}
& \Omega_{\text {free }}\left(\left(k_{\text {free }}+1\right) \Delta T\right)= \\
& \begin{cases}N E \times \sum_{k_{1}=0}^{N T_{1}-1}\left[F_{w, f}\left(k_{1} \Delta T\right)-F_{e, s}\left(k_{1} \Delta T\right)\right] & \text { if free }=1 \\
N E \times \sum_{k_{2}=0}^{N T_{2}-1}\left[F_{e, f}\left(k_{2} \Delta T\right)-F_{w, s}\left(k_{2} \Delta T\right)\right] & \text { if free }=2\end{cases}
\end{aligned}
$$

where free $=1$ and free $=2$ represent that the EV is in the working hours at the workplace and during rest hours at home, respectively; $N T_{1}$ is the total number of dispatching periods included in the working hours; $N T_{2}$ is the total number of dispatching periods included in the rest hours; $\Delta T$ is the time length of each dispatching period, $k_{1}=0,1,2, \ldots, N T_{1}-1, k_{2}=0,1,2, \ldots, N T_{2}-1$. This paper divides $24 \mathrm{~h}$ a day into 96 time periods, and each period is $15 \mathrm{~min}$.

However, with driving and charging demands, if the EV needs to be in a controllable state, not only does the EV need to be idle during the dispatching periods, but it also needs to be in a sufficient state of charge (SOC) for the user demand required before leaving the grid. The sequence diagram of the charging scenarios for judging whether the individual EVs are in a controllable state is shown in Figure 2. $t_{a, i}$ is the time when EV $i$ is connected to the grid, $t_{r, i}$ is the leaving time from the grid for EV $i$, $t_{e, i}$ is the ending time when EV $i$ charges the battery to the user's required SOC, $t_{p, i}$ and $t_{q, i}$ represent the start time of the $p$ - th and $q-t h$ dispatching of electricity grid for EV $i, t_{p+\Delta T, i}$ and $t_{q+\Delta T, i}$ represent 
the stop time of the $p$ - th and $q-t h$ dispatching of electricity grid for EV $i$, and $t_{d, i}$ is the leaving time when EV participates one dispatching period, $S O C_{s, i}$ is the state of charge when $\mathrm{EV} i$ is connected to the grid, $S O C_{r, i}$ is the required state of charge when EV $i$ leaves the grid, $S O C_{p, i}$ and $S O C_{q, i}$ are the initial state of charge of the $p-t h$ and $q$ - th dispatching of electricity grid for EV $i$, respectively.

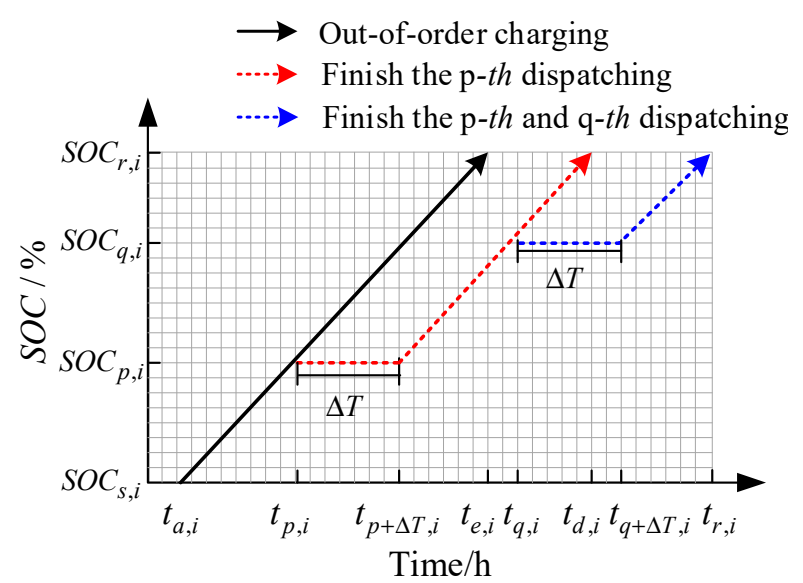

Figure 2. The sequence diagram for uncoordinated charging and coordinated charging of EVs.

In this figure, the black curve is the scenario where the EV is charged with constant power after connecting to the grid. The red curve indicates that the EV accepts the dispatching order at $t_{p, i}$ during the charging period and temporarily leaves the grid, and then reconnects to electricity grid for charging after the dispatching. Meanwhile, the blue curve shows the scenario in which the EV completes two dispatching orders of the grid. In addition, the EV is considered to be uncontrollable when the EV is charged with full power or the amount of charged energy for EV user demand is not satisfied before leaving the grid, i.e., the EV keeps charging during idle periods without reacting to the dispatch signal that interrupts its charging process. Namely, the sequence diagram for different charging scenarios shows that the conditions for judging whether a single $\mathrm{EV}$ is in a controllable state is $\overline{T_{i}}>0$, and the definition of $\overline{T_{i}}$ is as follows:

$$
\overline{T_{i}}=t_{r, i}-t_{a, i}-n \Delta T-\frac{\left(S O C_{r, i}-S O C_{n, i}\right) \times C_{i}}{P_{c h, i} \eta_{c h}}
$$

where $S O C_{n, i}$ is the state of charge after completing $n$ dispatching orders of EV $i, P_{c h, i}$ is the charging power of $\mathrm{EV} i, \eta_{c h}$ is the charging efficiency, $C_{i}$ is the battery capacity of EVs.

When $\overline{T_{i}}>0$, the individual EV is considered to be controllable. To summarize, the number of controllable EVs that can participate in the micro-grid dispatching in the same time period is taken as a set $\Omega_{\text {sch }}$, whose definition is expressed by Equation (8). This set contains EVs which can participate in the dispatching of power system under all scenarios in the time period $k$. Therefore, the expression of the controllable capacity of EVs in the time period $k$ is shown in Equation (9).

$$
\begin{gathered}
\Omega_{s c h}(k \Delta T)=\left\{\begin{array}{c}
i \mid S O C_{n, i}+\int_{t_{a, i}+n \Delta T}^{t_{r, i}} P_{c h, i} \eta_{c h} d t / C_{i} \\
\geq S O C_{r, i}, i \in \Omega_{\text {free }}(k \Delta T)
\end{array}\right\} \\
C_{d i s}(k \Delta T)=\sum_{i=1}^{\Omega_{s c h}(k \Delta T)} P_{c h, i}
\end{gathered}
$$

where $k=1,2,3, \ldots, N T, N T$ is the total number of time periods in a day and less than the 96 time periods. 


\section{EV User Comprehensive Satisfaction Degree Modeling}

The successful dispatching of the power system needs the active participation of EVs. Except for being concerned about whether the charging strategy can reach the required SOC of the EVs before leaving, EV users also need to consider factors such as the inconvenience of electricity consumption and economics when participating in dispatch. Since EV users with different preferences will choose diverse charging strategies in the face of the same incentives from the electricity grid, the comprehensive satisfaction degree model established in this section aims to analyze the impact of the EV users with different preferences on the choice of charging strategy.

Combining the diverse EV users' driving characteristics, as well as the economy and convenience of charging preferences, user economic satisfaction degree and electricity convenience satisfaction degree are selected as two indicators to measure comprehensive satisfaction degree as proposed in Equation (10). The comprehensive satisfaction degree function takes the choice of EV users into account, that is, the weight coefficients of the indicators of diverse EV users are different, which is defined as EV user preference coefficients in Section 3.3.

$$
R_{U S D, i}=f\left(R_{U S D, 1, i}, R_{U S D, 2, i}\right)
$$

where $R_{U S D, 1, i}$ and $R_{U S D, 2, i}$ are user economic satisfaction degree and electricity convenience satisfaction degree functions of $\mathrm{EV} i$, respectively.

\subsection{The Economic Satisfaction Degree of EV Users}

EV user economic satisfaction degree is an indicator that measures the relationship between the actual charging price given by the electricity grid and the expected charging price of the users. Different types of EV users' charging strategies will change in response to the changes in charging price, which will reduce charging costs in the premise of meeting the users' daily driving demands. The user economic satisfaction degree is defined as follows:

$$
R_{U S D, 1, i}=1-e^{-\alpha \frac{\lambda_{e x, i}}{\lambda}}
$$

where $\alpha$ is the impact factor of electricity price, whose value in this paper is 0.5 , and it is the same for different users [28]; $\lambda$ is the charging price given by the electricity grid; and $\lambda_{e x, i}$ is the expected charging price of EV $i$, whose value in this paper is different for normal, urgent, and economical EV users in the micro-grid, and can be set according to the actual situation. When the incentive price given by electricity grid is lower than the expected charging price, the user economic satisfaction degree is high, and increases with the decrease of charging price given by electricity grid.

\subsection{The Electricity Convenience Satisfaction Degree of EV Users}

The user electricity convenience satisfaction degree is an indicator to show the degree of changes in EV charging behaviors, e.g., the charging power and charging time. In Equation (12), $\int_{1}^{N T} L_{i, t} d t$ indicates the charging load of EV $i$ in entire time horizon under the peak-valley price. With the degree of changes in EV charging behaviors increases, the user electricity convenience satisfaction degree is gradually reduced, and we use $\int_{(k-1) \Delta T}^{k \Delta T}\left|L_{s c h, i, t}-L_{i, t}\right| d t$ to indicate the variation of load when EV $i$ changes its charging behavior in time period $k$, according to the dynamic charging price. After the dynamic time-of-use price is implemented in the dispatching period, the users can decrease the charging costs by changing the EV charging behaviors. If the variation of EV load caused by the change of charging behavior is high, i.e., the EV user prefers to transfer the charging load from the high price period to the low price period, then the user electricity convenience satisfaction degree is low. That is to say, EV users will exchange economic benefits with their own freedom of electricity consumption. If the variation of EV load caused by the change of charging behavior is low, then the user convenience 
satisfaction degree is high, which means that EV users prefer to charge as fast and as much as possible when they need it. Therefore, the electricity convenience satisfaction degree function can be expressed in Equation (12):

$$
R_{U S D, 2, i}=1-\frac{\int_{(k-1) \Delta T}^{k \Delta T}\left|L_{s c h, i, t}-L_{i, t}\right| d t}{\int_{1}^{N T} L_{i, t} d t}
$$

where $L_{s c h, i, t}$ is the charging load of EV $i$ in the time period $k$, after the dynamic time-of-use charging price is implemented; $L_{i, t}$ is the charging load of $\mathrm{EV} i$ in the time period $k$ under the peak-valley price; and NT represents the total time of a day.

\subsection{The Comprehensive Satisfaction Degree of EV Users}

The comprehensive satisfaction degree of $\mathrm{EV}$ users is characterized by user economic satisfaction degree and electricity convenience satisfaction degree, and can be calculated according to Equation (13), which reflects different charging strategy choices of EV users with different preferences.

$$
R_{U S D, i}= \begin{cases}\sum_{j=1}^{N S} s_{j, i} R_{U S D, j, i} & \forall R_{U S D, j, i} \in[0,1] \\ 0 & \text { others }\end{cases}
$$

where $s_{j, i}$ is the preference coefficient for satisfaction degree $j$ of EV user $i$, which embodies the importance of different types of satisfaction degree of each EV user. Meanwhile, the preference coefficients should satisfy the following relationship for EV user $i$ :

$$
\sum_{j=1}^{N S} s_{j, i}=1 \forall s_{j, i} \in[0,1]
$$

The preference coefficient $s_{j, i}$ has a significant influence on the charging strategy selection of EV users. The user economic satisfaction degree $R_{U S D, 1, i}$ indicates the degree of attraction of the charging price provided by the grid to the EV users during the dispatching period, and the corresponding preference coefficient $s_{1, i}$ represents the sensitivity of $\mathrm{EV}$ users to the change of the charging price. The electricity convenience satisfaction degree $R_{U S D, 2, i}$ expresses the degree of inconvenience of electricity consumption caused by changing the EV charging behavior, and the corresponding preference coefficient $s_{2, i}$ conveys the urgency of EV users' charging demand. This paper assumes that there are three types of EV users, including EV user types with normal, urgent, and economical charging demands. The preference coefficients are shown in Table 1 , and the comprehensive satisfaction degree is valued based on the sub-item satisfaction degrees and preference coefficients in Equation (13).

Table 1. Preference coefficients for different EV users.

\begin{tabular}{ccc}
\hline The Types of EV Users & $\boldsymbol{s}_{1, i}$ & $\boldsymbol{s}_{2, \boldsymbol{i}}$ \\
\hline Normal & 0.50 & 0.50 \\
Urgent & 0.35 & 0.65 \\
Economical & 0.65 & 0.35 \\
\hline
\end{tabular}

\section{A Pricing Strategy for EVs on Account of the Supply-Demand Relationship of the Micro-Grid}

For the moment, the generation of renewable energy such as wind power and photovoltaic is greatly affected by the external environment, which makes the output power intermittent and unstable. Thus, power shortage or excess frequently appears in the independent-operation micro-grid, resulting in the unsafe operation of the distribution network. At the same time, the uncoordinated charging behaviors of EVs have an enormous impact on the load, which will aggravate the low utilization rate of renewable energy and the imbalance between supply and demand of the micro-grid. 
In order to realize the effective dispatching of EVs, Section 3 fully considers the charging preference and choice of EV users, and establishes a comprehensive satisfaction degree model to determine the charging strategies for different EV users. This section further proposes a pricing strategy for EV charging, based on the coordination of supply and demand of the micro-grid, which considered the demand response of the user and implemented it in the day-ahead phase. Firstly, according to the prediction results of load and distributed power output, the next day's supply and demand imbalance power of the micro-grid is obtained, and the controllable capacity of EVs is predicted in each time period of the next day. Then, we consider the two indicators of EV users' economic satisfaction degree and convenience satisfaction degree as the basis for judging whether the EV participates in the dispatching. According to the dispatching order of the grid, the peak-valley price can be adjusted appropriately to guide the choice of EV users' charging strategies and so as to effective dispatch the EVs.

\subsection{The Structure of the Micro-Grid System with Large-Scale EV Cluster}

In the strategy raised in this paper, the development of dynamic time-of-use price involves information on the travel patterns of large-scale EVs, users' charging demands, personal preferences, and the dispatching instructions of the electricity grid. Thus, it is impossible for the grid to read the massive data of EVs directly and control the charging behaviors. Therefore, a method is adopted whereby the dispatching orders are given to EVs at the individual level, through the interaction between EV cluster aggregator and the grid. Meanwhile, the EV cluster aggregator will complete the autonomous functions of EVs, such as driving, parking, and charging actions, according to the users' demands and preferences.

The structure of the micro-grid system that integrates distributed generators and large-scale EVs, i.e., a large number of EVs, is shown in Figure 3. An electricity market framework is established by introducing several roles, including the dispatching management center (DMC), the EV cluster aggregator, and EV users. As the intermediary agent between the DMC and EV users, the EV cluster aggregator has the actual control right of EVs, and it will make arrangements for EVs charging based on the initial SOC, the leaving time from electricity grid, the expected SOC, and charging preferences uploaded by EV users, as well as the dispatching requirements of DMC. The DMC signs charging agreements with the EV users according to the electrical load and the feedback information from the EV cluster aggregator, to determine the charging price, charging periods, and electricity requirements of the users, and realize the effective management of the EV charging load.

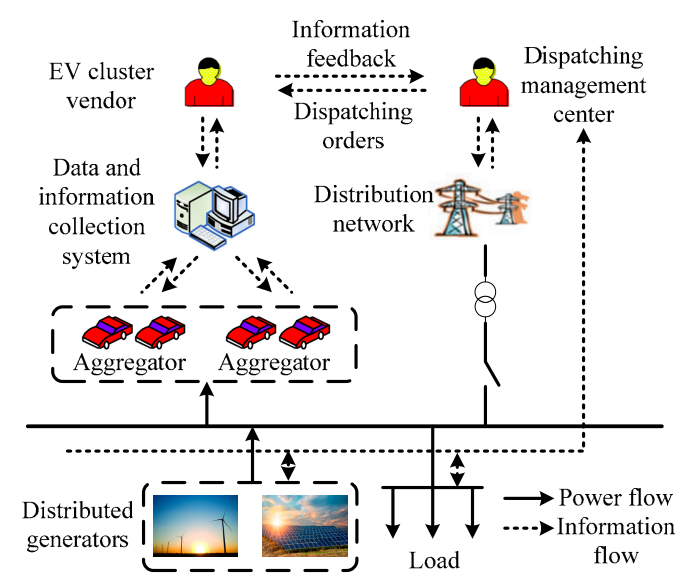

Figure 3. The structure of micro-grid system with large-scale EV cluster.

\subsection{Dynamic Time-Of-Use Pricing Strategy for EV Charging}

An EV cluster aggregator can adjust the economic satisfaction degree on the basis of the price sensitivity of different users, so as to guide EV users to change their charging behaviors by price signals, 
and meet the unbalanced demand of the micro-grid in each time period of the next day. The flow chart of dynamic time-of-use pricing strategy for EV charging is shown in Figure 4. This strategy consists of two parts: (1) in the first part, the EV cluster aggregator arranges the charging plans with the target of minimum charging cost of EV users guided by the peak-valley price; (2) on the basis of the electrical load obtained by the former part, the second part takes the balance of supply and demand of the micro-grid as the goal, to determine the dispatching requirements of the EV cluster for each time period, and continuously update the charging price. During the process, the price is restricted to the peak-valley price, generation, and transmission costs of renewable energy, and the comprehensive satisfaction degree of EV users, until the number of EVs participating in the dispatching can meet the demand as much as possible. The dynamic time-of-use charging price is calculated by following steps.

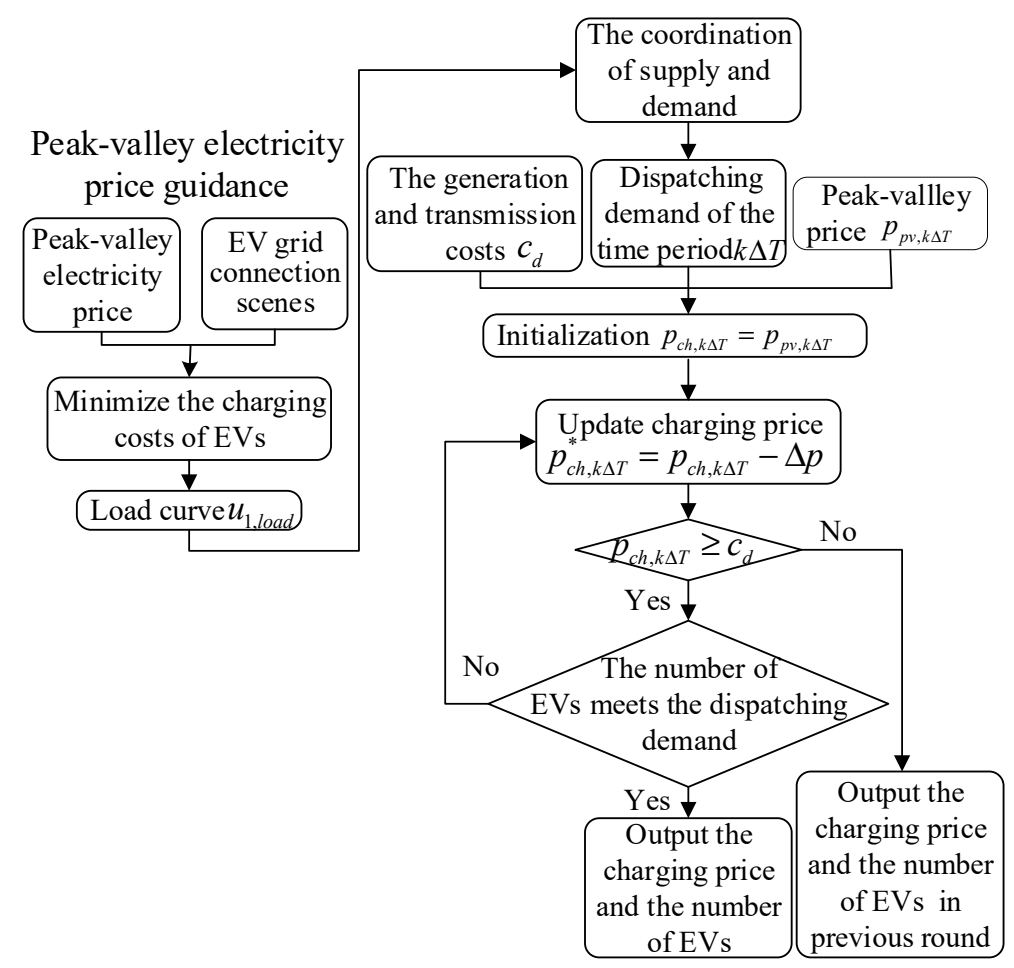

Figure 4. The flow chart of dynamic time-of-use pricing strategy for EV charging.

\subsubsection{Peak-Valley Electricity Price Guidance}

Based on grid connection scenes of $\mathrm{EV}$, the charging plans are arranged with the objective function of the minimum total charging costs of EV users under peak-valley price in Equation (15), and the electrical load curve obtained under the arranged charging plan is $u_{1, \text { load }}$.

$$
\min f=\min \sum_{i=1}^{N E} \sum_{k=1}^{N T} P_{c h, i} p_{p v, k \Delta T}
$$

where $p_{p v, k \Delta T}$ is the peak-valley price in the time period $k$ of the micro-grid.

\subsubsection{Calculation of the Dynamic Time-Of-Use Charging Price}

The peak-valley price is commonly formulated according to the electrical load of the grid. Since the output of distributed generators is unstable and the electrical load is fluctuating, the unbalanced power in the micro-grid is taken as the basis of formulating dynamic time-of-use price. Based on the load curve $u_{1, \text { load }}$ and the output of renewable energy, the balance of supply and demand of the grid is taken 
as the goal, to decide the dispatching demand for EV cluster in the time period $k$, which is shown in Equation (16):

$$
\Delta P_{k \Delta T}=P_{w, k \Delta T}+P_{P V, k \Delta T}-P_{l o a d, k \Delta T}
$$

where $P_{w, k \Delta T}$ is the output of wind turbines in the time period $k, P_{P V, k \Delta T}$ is the output of photovoltaic in the time period $k$, and $P_{\text {load }, k \Delta T}$ is the electrical load in the time period $k$ under peak-valley price of the micro-grid.

Considering the generation and transmission costs of renewable energy and the peak-valley price in the micro-grid, the dynamic time-of-use price of EVs can only be adjusted within a certain range. On the one hand, the adjusted charging price in the time period $k$ cannot be higher than the corresponding peak-valley price, otherwise the EV users will not be stimulated to participate in the load adjustment. On the other hand, the adjusted charging price should not be lower than the generation and transmission costs of renewable energy, in order not to reduce the operational economic efficiency of the entire micro-grid. Therefore, the peak-valley price $p_{p v, k \Delta T}$ and the generation and transmission costs of renewable energy $c_{d}$ are taken as the upper/lower limits of the charging price adjustment, respectively, and the dynamic time-of-use price in the time period $k$ is updated within this range. This paper treats the peak-valley price as the initial charging price, to maximize the economic benefits of the micro-grid. When the number of EVs that can be dispatched under the updated time-of-use price $p_{c h, k \Delta T}^{*}$ could meet the dispatching demand, the relevant number of EVs and the charging price $p_{c h, k \Delta T}$ can be obtained. If the updated time-of-use price $p_{c h, k \Delta T}^{*}$ is lower than the lower limit $c_{d}$, even when the number of EVs responding to the grid still cannot reach the dispatching demand, the previous charging price and EV number will be the output. In addition, the EV users who do not respond to dispatching signals in the above process are charged according to the peak-valley price.

The strategy proposed in this paper takes the balance of supply and demand of the micro-grid as the goal and fully considers the choice of EV users. The difference between the actual capacity of EVs responding to the grid and dispatching demand is set as the objective function as shown in Equation (17).

$$
\min P=\min \sum_{k=1}^{N T}\left(\sum_{i=1}^{\Omega_{\text {res }}(k \Delta T)} P_{c h, i}-\Delta P_{k \Delta T}\right)^{2}
$$

where $\Omega_{\text {res }}(k \Delta T)$ is the number of EVs responding to the grid in the time period $k$. It can be seen from the formula that this paper solves the convex quadratic programming problem, i.e., the solution is the global optimal solution.

The number of EVs responding to the dispatching periods is related to the users' driving demands, battery parameters, charging price, and user satisfaction degree. The constraint conditions are as follows:

1. The battery constraint of EV charging

In order to avoid overcharging resulting in the damage of battery lifetime, the battery of EV is assumed that can be charged within the maximum and minimum SOC. At the same time, the charging power is limited to the maximum and minimum values.

$$
\begin{gathered}
S O C_{i, t}=S O C_{i, t-\Delta t}+\int_{t-\Delta t}^{t} P_{c h, i} \eta_{c h} d t / C_{i} \\
S O C_{i}^{\min } \leq S O C_{i, t} \leq S O C_{i}^{\max } \\
P_{c h, i}^{\min } \leq P_{c h, i} \leq P_{c h, i}^{\max }
\end{gathered}
$$

where $S O C_{i, t}$ is the state of charge of EV $i$ at time $t, S O C_{i}^{\max }$ and $S O C_{i}^{\min }$ are the higher/lower limits of SOC of the EVs participating in the dispatching respectively. $P_{c h, i}^{\max }$ and $P_{c h, i}^{\min }$ are the higher/lower limits of charging power.

2. The charging requirements constraint for EVs 
The SOC at the leaving time from the grid should meet the minimum electricity required by the user for the next trip.

$$
\operatorname{SOC}_{n, i}+\int_{t_{a, i}+n \Delta T}^{t_{r, i}} P_{c h, i} \eta_{c h} d t / C_{i} \geq S O C_{r, i}
$$

3. The number constraint of EV charging

The number of EVs that participate in the dispatching should not be more than the number of controllable EVs in each time period.

$$
\Omega_{\text {res }}(k \Delta T) \leq \Omega_{s c h}(k \Delta T)
$$

where $\Omega_{\text {sch }}(k \Delta T)$ is the number of controllable EVs in the time period $k$.

4. The higher/lower constraints of charging price for EVs

The adjusted time-of-use charging price cannot be higher than the peak-valley price, or lower than the generation and transmission costs of renewable energy accordingly in each time period.

$$
c_{d} \leq p_{c h, k \Delta T} \leq p_{p v, k \Delta T}
$$

where $c_{d}$ is the generation and transmission costs of renewable energy of the micro-grid, and $p_{p v, k \Delta T}$ is the peak-valley price in the time period $k$.

5. The constraint of user comprehensive satisfaction degree

The user comprehensive satisfaction degree obtained by weighting sub-item satisfaction degrees should meet the minimum value that the user will be willing to participate in the power system dispatching.

$$
R_{U S D, i} \geq R_{U S D, i, \min }
$$

where $R_{U S D, i}$ is the user comprehensive satisfaction degree of $\mathrm{EV} i$, and $R_{U S D, i, \min }$ is the minimum comprehensive satisfaction degree of participating in the power system dispatching for EV $i$, whose value in this paper is 0.8 , and the minimum value of comprehensive satisfaction degree can be set according to the actual situation.

\section{Numerical Simulation Results}

This section solves the proposed formulations and applies the dynamic time-of-use pricing strategy to the development of charging price of electricity grid. Moreover, the overall operational efficiency and economy of the micro-grid and charging costs of EV users are analyzed after the implementation of the dynamic time-of-use charging price. Additionally, we evaluate the performance of the proposed scheme in MATLAB R2015b.

\subsection{Parameter Setting}

A micro-grid in a certain area is taken as an example which possesses 10 wind turbines and 150 photovoltaic arrays, and the simulation schematic diagram is shown in Figure 5. The rated power of a single wind turbine is $100 \mathrm{~kW}$, and the corresponding cut-in wind speed, cut-out wind speed, and rated wind speed are $3.5,25$, and $15 \mathrm{~m} / \mathrm{s}$ respectively. The photovoltaic array consists of $4 \times 5$ photovoltaic panels, with a rated power of $4 \mathrm{~kW}$. A total of $2000 \mathrm{EVs}$ are simulated in numerical simulations, and the relevant parameters are shown in Table 2. The charging mode of EVs is slow (AC) charging and users charge EVs through the public charging piles of EV cluster aggregators. In addition, the daily load of the micro-grid and the peak-valley price are shown in Tables A1 and A2 in the Appendix A. Above parameters and data used are based on the existing literature and the actual micro-grid project [28-30]. It should also be noted that the cost of generation and transmission of renewable energy is mainly composed of the generation cost of wind power and photovoltaic power, price inclusive tax and transmission price. This paper sets the generation and transmission cost for each period, as shown in Table A3 in the Appendix A [28]. At the same time, the micro-grid needs to purchase electricity 
from the external power system when the power generation of distributed generators in the micro-grid cannot meet the demand of basic load and EVs charging load. The electricity price of the external power system is shown in Table A4 in the Appendix A.

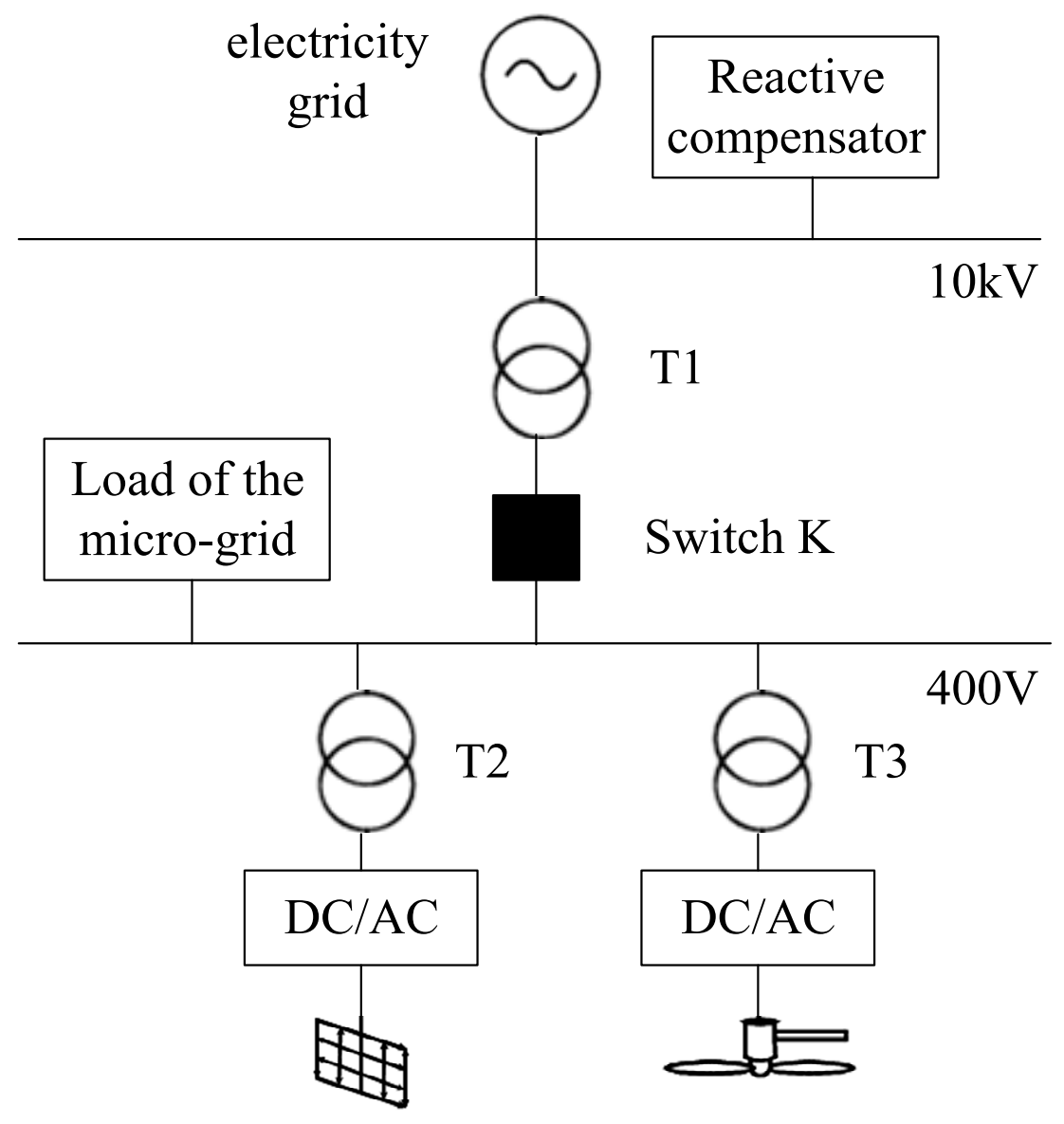

Figure 5. Simulation schematic diagram of the micro-grid.

Table 2. EV parameters and other relevant parameters.

\begin{tabular}{cccc}
\hline Parameters & Values & Parameters & Values \\
\hline$C_{i} / \mathrm{kWh}$ & 21.6 & $\eta_{c h} / \%$ & 0.9 \\
$p_{c h, i} / \mathrm{kW}$ & 3.6 & $E_{c} / \mathrm{kWh}^{-1} \mathrm{~km}^{-1}$ & 0.139 \\
$S O C_{\max } / \%$ & 100.0 & $S O C_{r, i} / \%$ & 0.6 \\
$S O C_{\min } / \%$ & 20.0 & $S / \mathrm{km}^{-1}$ & 28.5 \\
\hline
\end{tabular}

\subsection{Application of Dynamic Time-Of-Use Pricing Strategy for EVs}

\subsubsection{Simulation of Dynamic Time-Of-Use Charging Price and Participation Degree of Different EVs}

The dynamic charging price can reflect the short-term fluctuation of supply and demand in the micro-grid, which can effectively guide the EV users to make arrangement for charging, so as to stabilize load fluctuations in the micro-grid, promote the accommodation of renewable energy, and reduce the purchased electricity. Thus, based on the load curve obtained by guiding the charging behaviors of EVs with peak-valley price, we solve and publish the corresponding charging price in each time period through the proposed dynamic time-of-use pricing strategy, as shown in Figure 6a. In the simulation, the proportions of normal, urgent, and economical EV users in the micro-grid are set to $45 \%, 25 \%$ and $30 \%$, respectively, in order to fitting the actual operation of the micro-grid. 


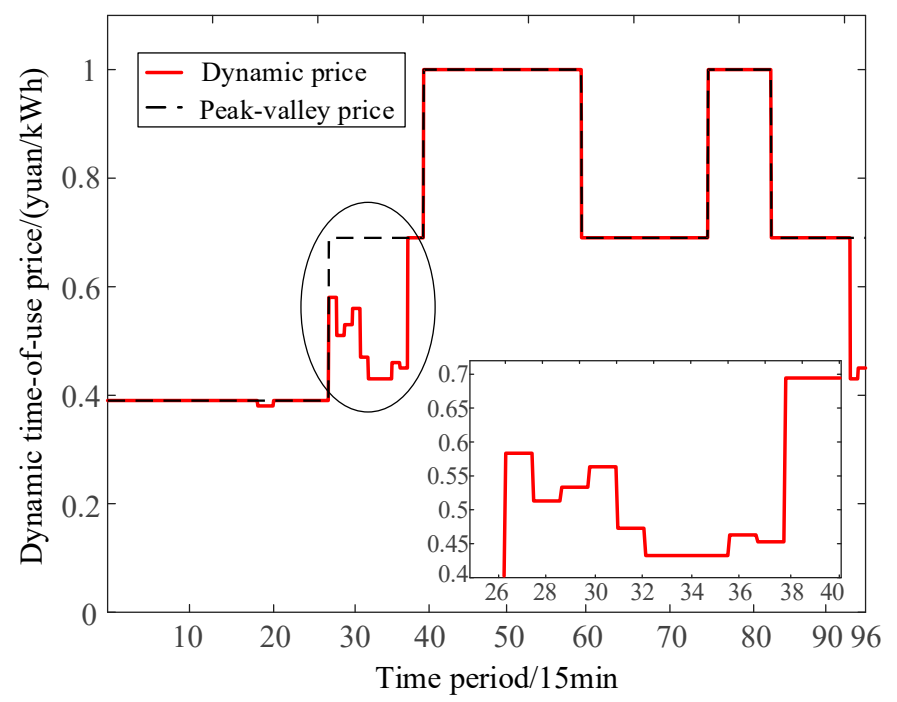

(a)

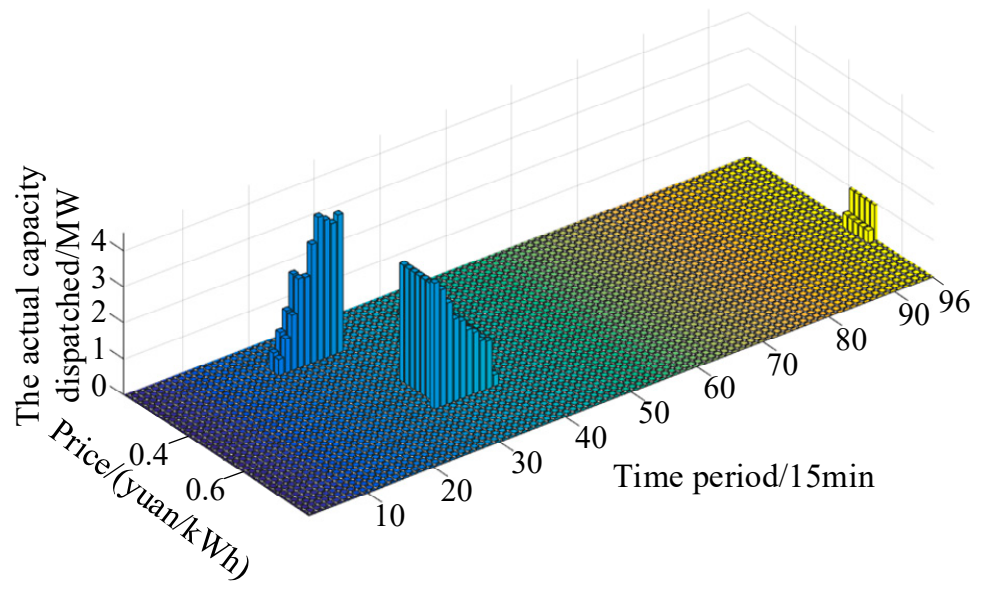

(b)

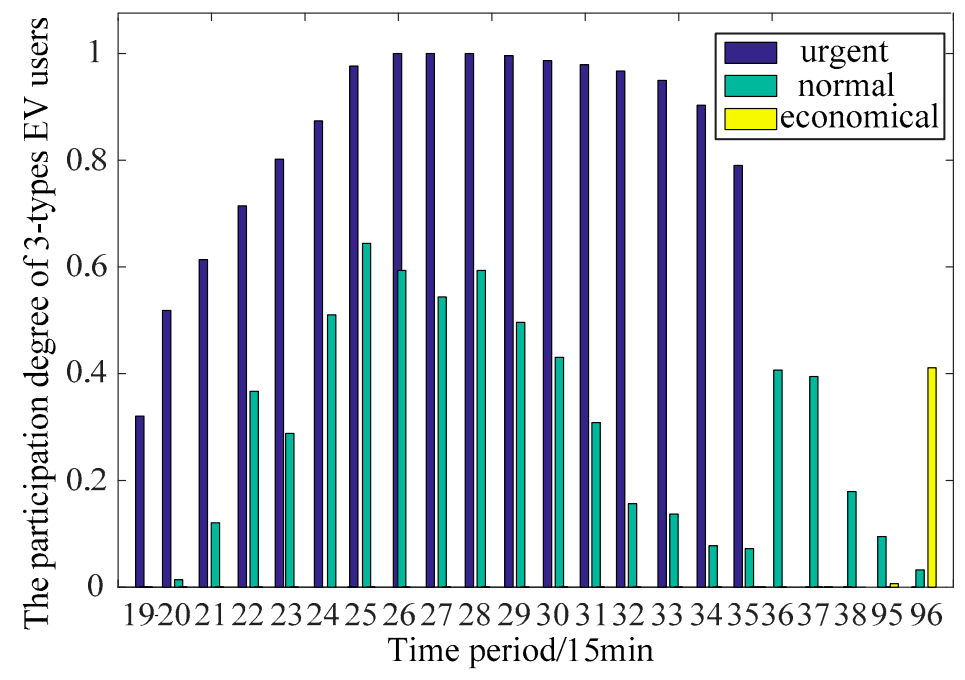

(c)

Figure 6. Simulation of dynamic time-of-use charging price and participation degree of different EVs. (a) Dynamic time-of-use charging price of the micro-grid in each period, (b) the relationship between dynamic time-of-use charging price and EV actual capacity dispatched, (c) the relative participation degree of the three types of EV users in the dispatching periods. 
Meanwhile, since the controllable capacity of EVs changes within $24 \mathrm{~h}$ of the day, the electricity grid will give diverse incentives for the same dispatching demand in different time periods. The degree of response of EV users is related to the dynamic charging price. In order to study the relationship between charging price and the controllable capacity of EVs, the dynamic charging price and the corresponding actual capacity of EVs are simulated and analyzed under different dispatching requirements for each period, and the results are shown in Figure 6b. Additionally, the EV users with different preferences will choose diverse charging strategies in the face of the same incentive from the electricity grid. In addition, making full use of the choice of EV users is conducive to studying the impact of EV cluster charging behavior on grid dispatching. Therefore, we discuss the participation degree of normal, urgent, and economical EV users in the dispatching period, as shown in Figure 6c.

It can be seen from Figure 6a that the non-overlapping portion of the dynamic time-of-use price and the peak-valley price represents the time periods in which the micro-grid has dispatching demands, and stimulates the EV users to transfer the charging load at a preferential price. In the time periods $T_{26}-T_{38}$ are the most concentrated periods of adjusting the charging price, the specific dispatching periods, and the corresponding price, and these are shown in the window of Figure 6a. The adjusted charging price for EVs lasts for at least $15 \mathrm{~min}$, which can well reflect the current operating state and the imbalance of supply and demand in the micro-grid. Moreover, the dynamic charging price will be more attractive than the constant peak-valley price, and can fully stimulate the participation of EV users, which makes it easy to realize the management of EV charging load, based on the user satisfaction degree.

Figure $6 \mathrm{~b}$ reflects that the micro-grid has dispatching demands in the time periods $T_{19}-T_{38}$ and $T_{95}-T_{96}$, in which the grid will gradually decrease the charging price, based on the peak-valley price to call for sufficient EVs. In a certain period, a lower charging price means that more EVs will participate in the dispatching, embodying the influence of economic satisfaction degree on the selection of EV users' charging strategies. It can be concluded from Figure $6 a, b$ that: (1) in the time periods $T_{21}-T_{25}$, although the micro-grid needs to dispatch a number of EVs, the obtained dynamic time-of-use price is equal to the peak-valley price. The reason is that the grid does not need to reduce the charging price to promote the participation of EV users, due to the fact that the price of 0.39 yuan $/ \mathrm{kWh}$ can dispatch enough capacity of EVs (in Figure $6 b$ ) to meet the requirements of the micro-grid. (2) In other time periods, the actual capacity of EVs which can be dispatched is below the demand (in Figure 6b). Then, the grid adjusts the dynamic time-of-use price, according to its balance of supply and demand within a certain range, and so as to make the number of responding EVs to reach the dispatching target as much as possible.

In the time periods $T_{19}-T_{35}$ in Figure $6 \mathrm{c}$, as the dispatching period increases, the participation degree of the urgent EV users first raises and then decreases. The participation degree of normal EV users is low, while the economical type of users is not involved in dispatching. The reasons can be attributed to the following two points: (1) when the dispatching demand of the micro-grid is low, there is no need to reduce the charging price substantially to attract economical EV users who are not sensitive to high electricity price, since the controllable capacity of the urgent and normal can fully meet the dispatching requirements. Meanwhile, due to the pressing need for charging of urgent EV users, the participation degree of them will be higher than that of the normal type. (2) The urgent EV users have higher participation degree in the early periods, but the insufficient controllable capacity leads to a low participation proportion in the later intervals. In the time periods $T_{36}-T_{38}$ and $T_{95}-T_{96}$, the controllable capacity of the urgent is zero, and only the normal and economical EV users participate in the dispatching.

As the dynamic pricing strategy for EVs charging in this paper is implemented in the day-ahead phase, if one or more parameters of EV change in real-time, it may cause the actual charging capacity of EVs to be different from the forecasting in the day-ahead. Therefore, we simulate the charging capacity of EVs under three different parameter settings, so as to study the impact of the five parameters on the charging capacity of EVs, i.e., the time leaving home, the time arriving at the workplace, the time 
leaving the workplace, the time arriving home, and the daily mileage of EVs in (1)-(5). The results are shown in Table A5 in the Appendix A. It can be seen from the table that the overall charging capacity of EVs does vary with the change of parameters, but the change is relatively small, and approximately within the range of $3 \%$. Therefore, the change of parameters will not have a significant impact on the overall availability of EV cluster in real-time dispatching.

\subsubsection{The Economic Research in Three Scenarios}

For the moment, the price mechanism for EV charging mainly includes fixed price, peak-valley price, and dynamic time-of-use price. In order to validate the effectiveness of the dynamic time-of-use price proposed in this paper in guiding the charging behaviors of EVs, the variation of the micro-grid load curves under uncoordinated charging, coordinated charging leaded by peak-valley price, and dynamic time-of-use price scenarios, are studied, as shown in Figure 7. The three charging situations in the figure show the different total charging energy of EVs, which is due to different target setting of the three charging situations, but all of the charging energy can satisfy the daily charging requirements of the EVs.

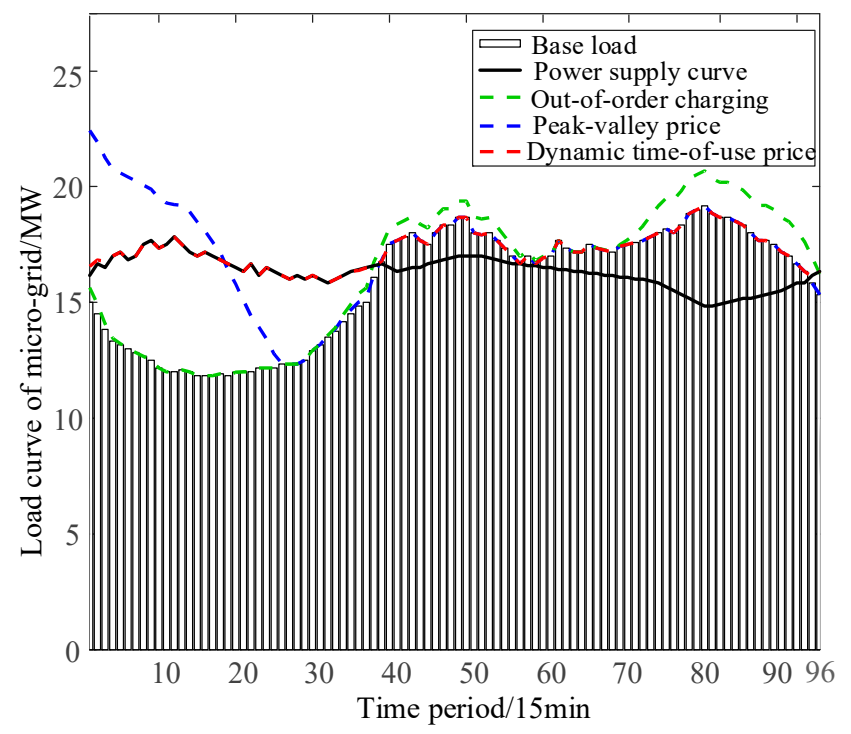

Figure 7. The load curves of the micro-grid in three charging situations of EVs.

In the uncoordinated charging mode, the EV users charge the batteries according to their own living habits, which will increase the peak-valley difference of the micro-grid and the electricity purchased from the external power system, thus resulting in a significant raise in the operation costs and the low utilization rate of renewable energy. Under the guidance of peak-valley price, the EV cluster aggregator will arrange for EVs to charge at valley-time, in order to reduce the charging fees, but this may cause a surge of load during the centralized charging periods. When the charging behaviors finish, the load will drop sharply, which has a huge impact on the safe and stable operation of the micro-grid. After adopting dynamic time-of-use price, the EV cluster aggregator makes arrangements for the EVs to charge, with the goal of balance between supply and demand of the micro-grid. Simulation results show that the charging behaviors of EV cluster can fully track the output of distributed generators under the guidance of dynamic time-of-use price, aiming to effectively stabilize the load fluctuation, improve the utilization rate of renewable energy, and reduce the electricity purchased from external power system.

Furthermore, by calculating the excess generation for distributed generators and electricity purchased from the external power system in different scenarios, the independence and economy of the operation of the micro grid under the three charging scenarios are further analyzed. In order to illustrate that the implementation of dynamic time-of-use price for EV charging will improve the 
economics of EV users, the unit charging cost of EV users under three charging situations is simulated. In addition, for the sake of simplicity, the main variable costs such as the penalty fees for abandonment of wind, photovoltaic, and electricity purchasing charges in three scenarios are compared. It is assumed that the penalty fees for abandonment of wind and photovoltaic are 0.88 yuan $/ \mathrm{kWh}$ [31]. The above simulation results and the respective decline rates after the implementation of peak-valley price and dynamic price compared with uncoordinated charging are shown in Tables 3 and 4 respectively.

Table 3. Excess generation for distributed generators and electricity purchased form the external power system in different scenarios.

\begin{tabular}{ccccc}
\hline $\begin{array}{c}\text { Charging } \\
\text { Scenarios }\end{array}$ & $\begin{array}{c}\text { Excess } \\
\text { Generation/kWh }\end{array}$ & $\begin{array}{c}\text { Decreased } \\
\text { Percentage }\end{array}$ & $\begin{array}{c}\text { Purchased } \\
\text { Electricity/kWh }\end{array}$ & $\begin{array}{c}\text { Decreased } \\
\text { Percentage }\end{array}$ \\
\hline Uncoordinated & 35,650 & $/$ & 37,930 & $/$ \\
charging & 14,270 & $59.9 \%$ & 36,080 & $4.9 \%$ \\
Peak-valley price & 0 & $100 \%$ & 21,820 & $42.5 \%$ \\
Dynamic price & & & \\
\hline
\end{tabular}

Table 4. The unit charging cost of EV users and overall operation costs of the micro-grid.

\begin{tabular}{ccccc}
\hline $\begin{array}{c}\text { Charging } \\
\text { Scenarios }\end{array}$ & $\begin{array}{c}\text { Unit } \\
\text { Cost/Yuan }\end{array}$ & $\begin{array}{c}\text { Decreased } \\
\text { Percentage }\end{array}$ & $\begin{array}{c}\text { Variable } \\
\text { Costs/Yuan }\end{array}$ & $\begin{array}{c}\text { Decreased } \\
\text { Percentage }\end{array}$ \\
\hline $\begin{array}{c}\text { Uncoordinated } \\
\text { charging }\end{array}$ & 0.82 & $/$ & $69,468.89$ & $/$ \\
Peak-valley price & 0.45 & $45.12 \%$ & $39,534.45$ & $43.09 \%$ \\
Dynamic price & 0.43 & $47.56 \%$ & $21,345.95$ & $69.27 \%$ \\
\hline
\end{tabular}

It can be seen from Tables 3 and 4 that the excess generation for distributed generators and electricity purchased from the external power system are the highest among the three charging scenarios when EVs are charged uncoordinatedly, which indicates that the micro-grid has a large imbalance between power supply and demand. Moreover, the unit charging cost of EV users and the main variable costs of the micro-grid are also the highest, which reflects that the low utilization rate of renewable energy at night and the charging behaviors of EV users during the peak-load periods result in a continuous increase of the charging load. In summary, from the decline of the four indicators, the operational independence under the dynamic time-of-use price is the highest, which does not only improve the utilization of renewable energy, but could also reduce the electricity purchased from the external power system and enhance the economy of the micro-grid.

The work of this paper is compared with the recently published reference [32] to verify the feasibility and rationality of the proposed strategy. When the EV number is set to be 2000 in the case, the charging cost of EVs under proposed method and under the peak-valley price in [32] are shown in Table 5 .

Table 5. The comparison of the charging cost of EV between the two strategies.

\begin{tabular}{cc}
\hline Strategy & The Charging Cost of EV Users/Yuan \\
\hline The dynamic time-of-use price & $14,035.40$ \\
The peak-valley price & $14,400.00$ \\
\hline
\end{tabular}

It can be seen from the above table that the charging cost of EVs using this method is slightly lower than that under peak-valley price, which is due to the fact that the number of EVs participating in the dispatching is few in the two cases. Since the total charging capacity of EVs will increase dramatically with the increase of the number of EVs in the future. Therefore, the charging cost of EVs using this method will be markedly lower than that under peak-valley price. Secondly, the implementation of dynamic time-of-use pricing strategy for EVs can reduce the electricity purchased from external power 
system, so as to improve the economic operation of the micro-grid. Meanwhile, the dynamic price of EVs obtained in this paper adopted the peak-valley price as the upper limit, and the generation and transmission cost of distributed generation as the lower limit. The obtained dynamic charging price of this paper is 0.38 yuan $/ \mathrm{kWh} \mathrm{1}$ yuan $/ \mathrm{kWh}$, which is close to 0.5 yuan $/ \mathrm{kWh} 0.8$ yuan $/ \mathrm{kWh}$ in the reference. Therefore, the pricing strategy of this paper is feasible and rational.

\subsection{Sensitivity Analysis of Different Charging Preferences of EV Users}

The dynamic time-of-use price is formulated for the micro-grid containing different types of EV users in the simulation of the previous section. However, the charging preferences of EV users will have a significant influence on the final results of charging price and the dispatching effect of the micro-grid. Thus, when the proportions of normal, urgent, and economical EV users are set to $100 \%$, $100 \%$, and $100 \%$ respectively, the dynamic time-of-use price for the above three types of EV users is formulated, so as to analyze the influence of EV users with different preferences on the selection of charging strategies. The results are shown in three corresponding curves in Figure 8. The sub-item and comprehensive user satisfaction degrees of the three types of EV users are simulated and analyzed, as shown in Table 6.

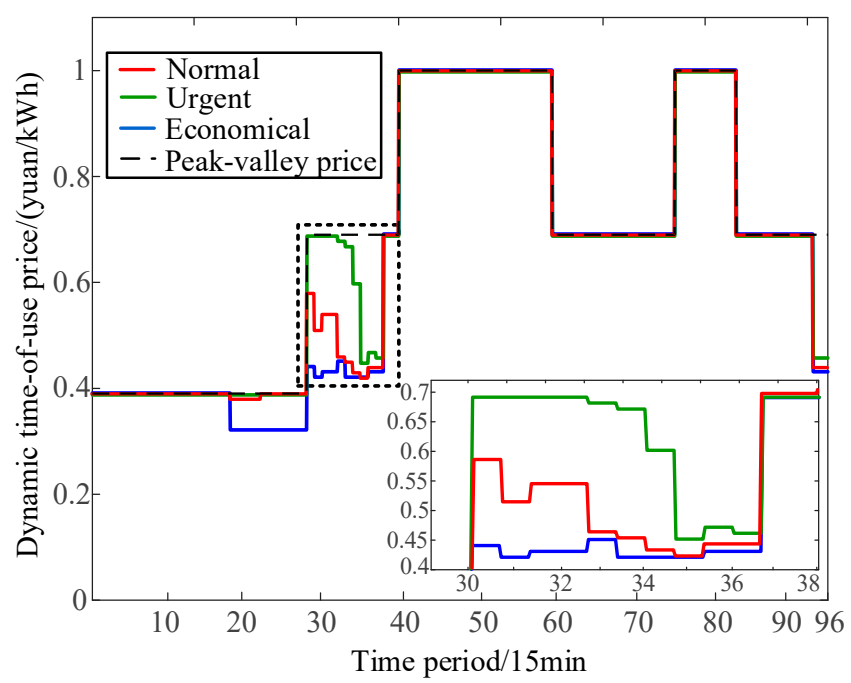

Figure 8. Dynamic time-of-use charging price for normal, urgent and economical EV users in each period.

Table 6. The sub-item and comprehensive satisfaction degrees of three types of EV users.

\begin{tabular}{cccc}
\hline The Types of EV Users & $\boldsymbol{R}_{\boldsymbol{U S D , 1}}$ & $\boldsymbol{R}_{\boldsymbol{U S D}, 2}$ & $\boldsymbol{R}_{\boldsymbol{U S D}}$ \\
\hline Normal & 0.5259 & 0.9823 & 0.7601 \\
Urgent & 0.4764 & 0.9960 & 0.8036 \\
Economical & 0.5934 & 0.9601 & 0.7527 \\
\hline
\end{tabular}

From Figure 8 and Table 6, we can see that the urgent EV users with eager charging requirements have lower sensitivity to the changes in charging price, compared to the normal and economical EV users. Therefore, they will sacrifice part of the economic benefits to obtain the charging service from the electricity grid, and the corresponding charging price for each time period is higher than that of the other two types of EV users, leading to the low economic satisfaction degree and high electricity convenience satisfaction degree of urgent EV users. For economical users, a lower charging price needs to be published to encourage this type of EV users to charge in the dispatching periods. Thus, the economical EV users have higher economic satisfaction degree and lower electricity convenience satisfaction degree, which means that they are willing to exchange electricity convenience for more economic benefits. 
To sum up, in the case of the same dispatching demand of a certain time period, the charging price for calling the urgent EV users is the highest, while the price for dispatching the economical is the lowest. In other words, the final dynamic time-of-use price will not exceed the above two limit values, regardless of the proportion of different types of EV users in the micro-grid.

The final results will show differences when different types of EV users participate in micro-grid dispatching. In order to reflect the different dispatching results of the normal, urgent, and economical EV users, due to their diverse charging strategies under the guidance of the dynamic time-of-use price, the impact of three types of EV users with different charging preferences on the results of micro-grid dispatching are simulated and analyzed, as shown in Figure 9.

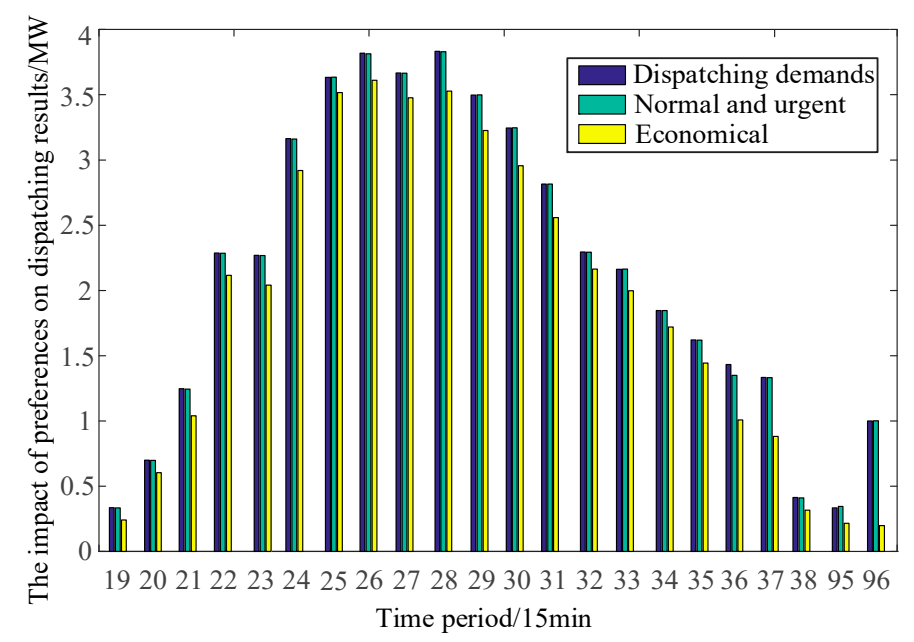

Figure 9. The impact of three types preferences on the dispatching results of the micro-grid.

The Figure 9 illustrates that the charging behaviors of economical EVs cannot fully track the output of the renewable energy when only the economical EV users participate in the dispatching, even if the grid gives a low charging price, which reflects that the dispatching effect of this type of EV users is the worst of the three. A high percentage of economical EVs will decrease the utilization rate of renewable energy. For the urgent and normal types of EV users, the electricity generated by distributed power sources can be completely absorbed under the guidance of their respective dynamic time-of-use price. Since the price of encouraging normal EV users is higher than that of the urgent, the urgent will be preferentially selected as the vehicles participating in the dispatching. That is to say, the more urgent EV users exist, the higher the overall economy and independence of the micro-grid will be.

\section{Conclusions}

The application of the EV charging load management method does not only help to reduce the huge impact on the grid caused by uncoordinated charging characteristic and choice of large-scale EVs, but also improves the operation efficiency of the power system, as well as the service quality. Meanwhile, reasonable charging price is the fundamental driving force for users to participate in the dispatching of electricity grid effectively, as EVs are taking a greater share in the vehicle market. This paper proposes a dynamic time-of-use pricing strategy for EV charging, fully considering the individual driving characteristics and satisfaction degree of EV users, which aims to achieve the goal of friendly charging for the micro-grid.

Through the numerical stimulation results, the dynamic time-of-use charging price, obtained according to the information from the driving demands, users' preferences, and the balance of supply and demand of the micro-grid, can effectively guide EV users to transfer charging load, and improve the operational independence and economy of the micro-grid. Meanwhile, it has been demonstrated that significant financial benefits are offered to the participants, and the cost of EV utilization and the operational cost of the electricity grid are decreased by this strategy. The research of the dynamic 
time-of-use pricing strategy put forward in this paper provides the foundation for the formulation of EV charging price. In the subsequent work, we will verify the effectiveness of the dynamic pricing strategy proposed in this paper through experiments. Additionally, we will further study the influence of EV users' interest on the amount of discharge energy, and develop a scheme to guide the discharging process of EV users.

Author Contributions: Conceptualization, Q.Z. and Y.H.; methodology, Y.H. and W.T.; software, Y.H.; validation, Y.H., W.T. and C.L.; formal analysis, Q.Z.; investigation, Z.D.; resources, W.T.; data curation, C.L.; writing-original draft preparation, Y.H.; writing-review and editing, Q.Z.; visualization, Z.D.; supervision, C.L.; project administration, W.T.; funding acquisition, Q.Z. All authors have read and agreed to the published version of the manuscript.

Funding: This research was surpported by the National Natural Science Foundation of China (51507022).

Conflicts of Interest: The authors declare no conflict of interest.

\section{Appendix A}

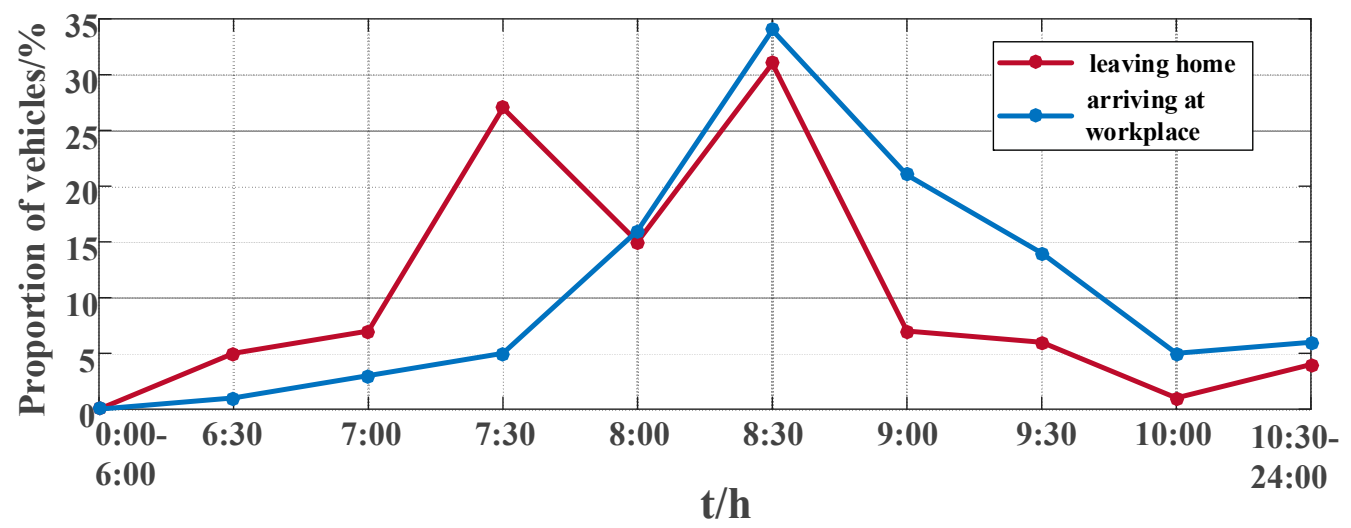

Figure A1. Departure and arrival time of vehicles for work.

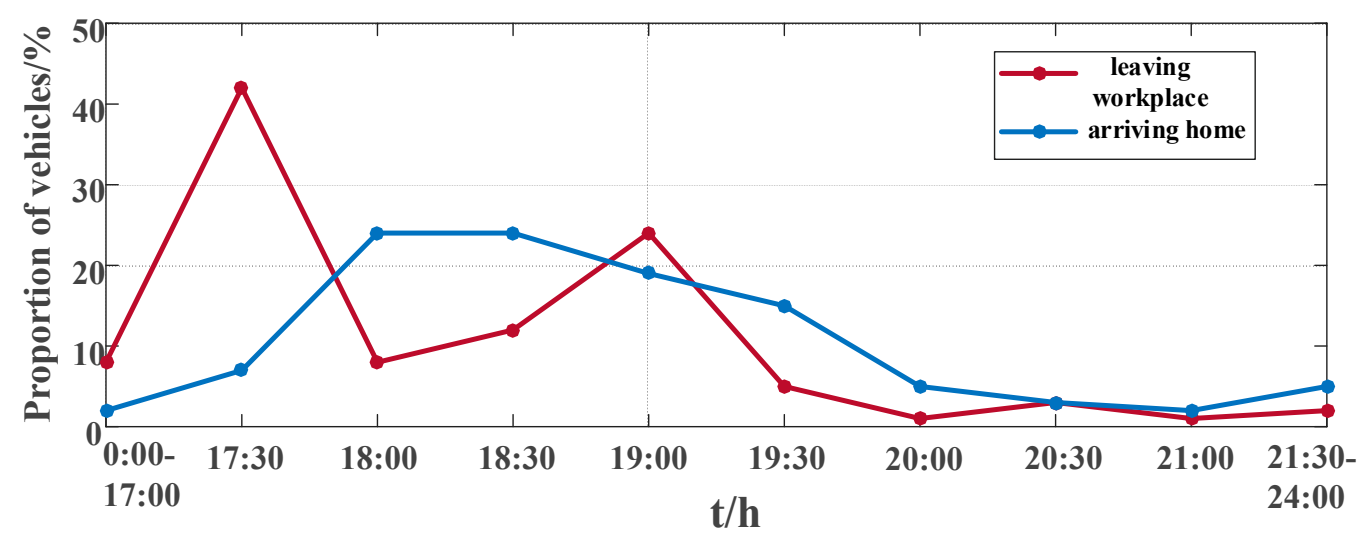

Figure A2. Departure and arrival time of vehicles for off-duty. 
Table A1. Daily load of the micro-grid.

\begin{tabular}{|c|c|c|c|c|c|c|c|c|}
\hline Period & 1 & 2 & 3 & 4 & 5 & 6 & 7 & 8 \\
\hline Power/MW & 15.0 & 14.5 & 13.8 & 13.3 & 13.2 & 13.0 & 12.8 & 12.6 \\
\hline Period & 9 & 10 & 11 & 12 & 13 & 14 & 15 & 16 \\
\hline Power/MW & 12.5 & 12.2 & 12.0 & 12.0 & 12.1 & 12.0 & 11.8 & 11.8 \\
\hline Period & 17 & 18 & 19 & 20 & 21 & 22 & 23 & 24 \\
\hline Power/MW & 11.8 & 11.9 & 11.9 & 11.9 & 12.0 & 12.0 & 12.2 & 12.2 \\
\hline Period & 25 & 26 & 27 & 28 & 29 & 30 & 31 & 32 \\
\hline Power/MW & 12.2 & 12.3 & 12.3 & 12.3 & 12.5 & 12.9 & 13.2 & 13.5 \\
\hline Period & 33 & 34 & 35 & 36 & 37 & 38 & 39 & 40 \\
\hline Power/MW & 13.8 & 14.2 & 14.5 & 14.8 & 15.0 & 16.0 & 16.8 & 17.5 \\
\hline Period & 41 & 42 & 43 & 44 & 45 & 46 & 47 & 48 \\
\hline Power/MW & 17.6 & 17.8 & 18.0 & 17.6 & 17.5 & 18.0 & 18.3 & 18.3 \\
\hline Period & 49 & 50 & 51 & 52 & 53 & 54 & 55 & 56 \\
\hline Power/MW & 18.7 & 18.7 & 18.0 & 17.9 & 18.0 & 17.7 & 17.3 & 17.0 \\
\hline Period & 57 & 58 & 59 & 60 & 61 & 62 & 63 & 64 \\
\hline Power/MW & 16.7 & 17.0 & 16.7 & 16.9 & 17.0 & 17.7 & 17.3 & 17.2 \\
\hline Period & 65 & 66 & 67 & 68 & 69 & 70 & 71 & 72 \\
\hline Power/MW & 17.2 & 17.5 & 17.3 & 17.3 & 17.2 & 17.4 & 17.5 & 17.6 \\
\hline Period & 73 & 74 & 75 & 76 & 77 & 78 & 79 & 80 \\
\hline Power/MW & 17.7 & 17.8 & 18.0 & 18.2 & 18.0 & 18.3 & 18.8 & 19.0 \\
\hline Period & 81 & 82 & 83 & 84 & 85 & 86 & 87 & 88 \\
\hline Power/MW & 19.2 & 18.8 & 18.7 & 18.7 & 18.5 & 18.3 & 18.0 & 17.7 \\
\hline Period & 89 & 90 & 91 & 92 & 93 & 94 & 95 & 96 \\
\hline Power/MW & 17.7 & 17.5 & 17.2 & 17.0 & 16.7 & 16.3 & 15.8 & 15.3 \\
\hline
\end{tabular}

Table A2. Peak-valley charging price of the micro-grid.

\begin{tabular}{cc}
\hline Period & Price/(Yuan/kWh) \\
\hline Valley periods (0:00 07:00) & 0.39 \\
Normal periods (07:00 10:00, 15:00 19:00, 21:00 24:00) & 0.69 \\
Peak periods (10:00 15:00, 19:00 21:00) & 1.00 \\
\hline
\end{tabular}

Table A3. The costs of generation and transmission of renewable energy.

\begin{tabular}{cc}
\hline Period & Price/(Yuan/kWh) \\
\hline Valley periods (0:00 07:00) & 0.32 \\
Normal periods (07:00 10:00, 15:00 19:00, 21:00 24:00) & 0.42 \\
Peak periods (10:00 15:00, 19:00 21:00) & 0.65 \\
\hline
\end{tabular}

Table A4. Purchase price from the external power system.

\begin{tabular}{cc}
\hline Period & Price/(Yuan/kWh) \\
\hline Valley periods (23:00 07:00) & 0.3946 \\
Normal periods (07:00 10:00, 15:00 18:00, 21:00 23:00) & 0.6950 \\
Peak periods (10:00 15:00, 18:00 21:00) & 1.0044 \\
\hline
\end{tabular}


Table A5. The charging capacity of EVs under three different parameter settings.

\begin{tabular}{ccccc}
\hline $\begin{array}{c}\text { The Dispatching } \\
\text { Period }\end{array}$ & $\begin{array}{c}\text { The First } \\
\text { Parameter Setting } \\
\mathbf{( k W )}\end{array}$ & $\begin{array}{c}\text { The Second } \\
\text { Parameter Setting } \\
\mathbf{( k W )}\end{array}$ & $\begin{array}{c}\text { The Third } \\
\text { Parameter Setting } \\
\mathbf{( k W )}\end{array}$ & $\begin{array}{c}\text { The Percentage of } \\
\text { the Absolute } \\
\text { Deviation (\%) }\end{array}$ \\
\hline 19 & 565.2 & 550.8 & 558 & 2.5 \\
\hline 20 & 1069.2 & 1044 & 1062 & 2.4 \\
\hline 21 & 1627.2 & 1591.2 & 1598.4 & 2.2 \\
\hline 22 & 2577.6 & 2595.6 & 2592 & 0.7 \\
\hline 23 & 2498.4 & 2473.2 & 3348 & 1.0 \\
\hline 24 & 3358.8 & 3340.8 & 3988.8 & 0.5 \\
\hline 25 & 4014 & 3985.2 & 3834 & 0.7 \\
\hline 26 & 3834 & 3834 & 3657.6 & 0.0 \\
\hline 27 & 3668.4 & 3657.6 & 3834 & 0.3 \\
\hline 28 & 3837.6 & 3826.8 & 3502.8 & 0.3 \\
\hline 29 & 3502.8 & 3502.8 & 3247.2 & 0.0 \\
\hline 30 & 3247.2 & 3250.8 & 2818.8 & 0.1 \\
\hline 31 & 2836.8 & 2818.8 & 2329.2 & 0.6 \\
\hline 32 & 2300.4 & 2300.4 & 2228.4 & 1.2 \\
\hline 33 & 2192.4 & 2185.2 & 1868.4 & 1.9 \\
\hline 34 & 1890 & 1879.2 & 1634.4 & 1.1 \\
\hline 35 & 1666.8 & 1620 & 828 & 2.9 \\
\hline & 820.8 & 846 & & 248 \\
\hline
\end{tabular}

\section{References}

1. Shi, J.; Liu, Y.; Tang, Y.; Deng, J. Application of a hybrid energy storage system in the fast charging station of electric vehicles. IET Gener. Transm. Distrib. 2016, 10, 1092-1097.

2. Richardson, P.; Flynn, D.; Keane, A. Optimal charging of electric vehicles in low-voltage distribution systems. IEEE Trans. Power Sys. 2012, 27, 268-279. [CrossRef]

3. Christensen, T.B.; Wells, P.; Cipcigan, L. Can innovative business models overcome resistance to electric vehicles? Better place and battery electric cars in Denmark. Energy Policy 2012, 48, 498-505. [CrossRef]

4. Karfopoulos, E.L.; Hatziargyriou, N.D. A multi-agent system for controlled charging of a large population of electric vehicles. IEEE Trans. Power Syst. 2013, 28, 1196-1204. [CrossRef]

5. Hu, J.; You, S.; Lind, M.; Ostergaard, J. Coordinated charging of electric vehicles for congestion prevention in the distribution grid. IEEE Trans. Smart Grid. 2014, 5, 703-711. [CrossRef]

6. Duvall, M.; Knipping, E. Environmental Assessment of Plug-In Hybrid Electric Vehicles. U.S. Patent 1,015,325, 1 January 2007.

7. Floch, C.L.; Belletti, F.; Saxena, S.; Bayen, A.M.; Moura, S. Distributed optimal charging of electric vehicles for demand response and load shaping. In Proceedings of the IEEE CDC, Osaka, Japan, 15-18 December 2015.

8. Xi, X.; Sioshansi, R. Using price-based signals to control plug-in electric vehicle fleet charging. IEEE Trans. Smart Grid. 2014, 5, 1451-1464. [CrossRef]

9. Zhang, L.; Li, Y. A Game-Theoretic Approach to Optimal Scheduling of Parking-Lot Electric Vehicle Charging. IEEE Trans. Veh. Technol. 2016, 65, 4068-4078. [CrossRef]

10. Bashash, S.; Fathy, H.K. Cost-optimal charging of plug-in hybrid electric vehicles under time-varying electricity price signals. IEEE Trans. Intell. Transp. Syst. 2014, 15, 1958-1968. [CrossRef]

11. Yang, X.; Su, J.; Lv, Z. Overview on Micro-grid Technology. Proc. CSEE 2014, 34, 57-70.

12. Cao, Y.; Tang, S.; Li, C.; Zhang, P.; Tan, Y.; Zhang, Z.; Li, J. An optimized EV charging model considering TOU price and SOC curve. IEEE Trans. Smart Grid. 2012, 3, 388-393. [CrossRef] 
13. Is It Necessary to Implement a TOU Price for Electric Vehicle Charging? Available online: https://www.sohu. com/a/220983003_100063272 (accessed on 9 September 2019).

14. Limmer, S. Dynamic Pricing for Electric Vehicle Charging-A Literature Review. Energies 2019, $12,3574$. [CrossRef]

15. Korkas, C.D.; Baldi, S.; Yuan, S.; Kosmatopoulos, E.B. An Adaptive Learning-Based Approach for Nearly Optimal Dynamic Charging of Electric Vehicle Fleets. IEEE Trans. Intell. Transp. Syst. 2018, 19, 2066-2075. [CrossRef]

16. Subramanian, V.; Das, T.K. A Two-layer Model for Dynamic Pricing of Electricity and Optimal Charging of Electric Vehicles under Price Spikes. Energy 2019, 1266-1277. [CrossRef]

17. Limmer, S.; Rodemann, T. Peak Load Reduction through Dynamic Pricing for Electric Vehicle Charging. Int. J. Electr. Power Energy Syst. 2019, 117-128. [CrossRef]

18. Zhang, L.; Li, Y. Optimal Management for Parking-Lot Electric Vehicle Charging by Two-Stage Approximate Dynamic Programming. IEEE Trans. Smart Grid 2017, 8, 1722-1730. [CrossRef]

19. Xu, Z.; Hu, Z.; Song, Y.; Zhang, H.; Chen, X. Coordinated charging strategy for PEV charging stations based on dynamic time-of-use tariffs. Proc. CSEE 2014, 34, 3638-3646.

20. Zhao, X.; Wang, S.; Wu, X.; Liu, J. Coordinated Control Strategy Research of Micro-Grid Including Distributed Generations and Electric Vehicles. Power Syst. Technol. 2016, 40, 3732-3740.

21. Daina, N.; Sivakumar, A.; Polak, J.W. Electric Vehicle Charging Choices: Modelling and Implications for Smart Charging Services. Trans. Res. Part C Emerg. Technol. 2017, 36-56. [CrossRef]

22. Biswas, M.M.; Azim, M.S.; Saha, T.K.; Zobayer, U.; Urmi, M.C. Towards implementation of smart grid: An updated review on electrical energy storage systems. Smart Grid Renew. Energy 2013, 4, 122-132. [CrossRef]

23. Luo, Z.; Hu, Z.; Song, Y.; Xu, Z.; Jia, L. Study on charging load modeling and coordinated charging of electric vehicles under battery swapping modes. Proc. CSEE 2012, 32, 1-10.

24. Yang, B.; Wang, L.; Liao, C. Research on power-charging demand of large-scale electric vehicles and its impacting factors. Trans. China Electrotech. Soc. 2013, 28, 22-27.

25. 2011 Beijing Traffic Development Annual Report. Available online: http://www.beijing.gov.cn/zfxxgk/110018/ gzzj53/2012-07/16/content_312307.shtml (accessed on 8 July 2017).

26. Yang, J. Researcher on the Electric Vehicles Charging Load Forecasting Method and the Strategy of Charging Control. Master's Thesis, Hunan University, Hunan, China, 2015.

27. US Department of Transportation. Federal Highway Administration, 2009 National Household Travel Survey. Available online: http://nhts.ornl.gov (accessed on 22 July 2017).

28. Piao, L.; Ai, Q.; Yu, Z.; Chen, J. Multi-agent-based pricing strategy for electric vehicle charging considering customer satisfaction degree. Autom. Electr. Power Syst. 2015, 39, 68-76.

29. Zhou, T.; Sun, W. Electric vehicle-to-grid technology based on micro-grid. Autom. Electr. Power Syst. 2018, 42, 98-104.

30. Turpan, Xinjiang, to Build a "Micro-Grid" in the Gobi Desert. Available online: http://www.gov.cn/xinwen/ 2019-12/20/content_5462797.htm\#1 (accessed on 25 December 2019).

31. Wang, Z. Research of Short-Term Operation Optimization of Power System with Large-Scale Renewable Generation. Master's Thesis, Huazhong University of Science and Technology, Wuhan, China, 2014.

32. Chen, J.; Yang, J.; Zhu, J.; Li, X.; Tang, Y. An optimal regional time-of-use charging price model for electric vehicles. In Proceedings of the IEEE Power Energy Society General Meeting, Chicago, IL, USA, 16-20 July 2017.

(C) 2020 by the authors. Licensee MDPI, Basel, Switzerland. This article is an open access article distributed under the terms and conditions of the Creative Commons Attribution (CC BY) license (http://creativecommons.org/licenses/by/4.0/). 